\title{
Exploring alternative routes to realising the benefits of simulation in healthcare
}

\author{
J Bowers, M Ghattas and G Mould
}

\begin{abstract}
Discrete event simulation should offer numerous benefits in designing healthcare systems but the reality is often problematic. Healthcare modelling faces particular challenges: genuine, fundamental variations in practice and an opposition to any suggestion of standardisation from some professional groups. This paper compares the experiences of developing a new simulation in an Accident and Emergency (A\&E) Department, a subsequent adaptation for modelling an outpatient clinic and applications of a generic A\&E simulation. These studies provide examples of three distinct approaches to realising the potential benefits of simulation: the bespoke, the reuse and the generic route. Reuse has many advantages: it is relatively efficient in exploiting previous modelling experience, delivering timely results while providing scope for adaptations to local practice. Explicitly demonstrating this willingness to adapt to local conditions and engaging with stakeholders is particularly important in healthcare simulation.
\end{abstract}

Keywords: health service; emergency departments; simulation

\section{Background}

Discrete Event Simulation (DES) has been extensively employed in analysing and designing healthcare systems (Jun et al, 1999). Although it is generally believed that simulation should offer many benefits in the organisation of healthcare delivery, there is comparatively little objective evidence of success (Fone et al, 2003). This deficiency may be a function of timescale, with publication occurring before any substantial validation could be completed. Furthermore simulation is often undertaken in conjunction with other management interventions in a changing environment and attributing improvements to any one factor is always difficult. Although, such problems might be common to all simulation applications, cross sector comparisons suggest that simulation has had considerably more success in other areas, such as commerce and defence (Naseer et al, 2008; Jahangirian et al, 2010). While much of the debate about healthcare simulation focuses on the United Kingdom's National Health Service (NHS), there is similar concern about the barriers to implementation in healthcare systems in other countries and notably the United States (Lowery, 1994). The particular challenge of healthcare simulation has been recognised in the commissioning of the Research Into Global Healthcare Tools project (Naseer at al, 2010) examining the problems identified in surveys of experts (Eldabi et al, 2007), observations from personal experiences (Brailsford et al, 2009) and literature reviews (Jahangirian et al, 2010).

The current paper examines these challenges to realising the potential for simulation in healthcare through a comparison of three case studies adopting different implementation routes: a bespoke simulation, a model reusing components and an application of a generic model. The bespoke Accident and Emergency (A\&E) Department simulation and the reuse orthopaedic clinic model were developed as part of a larger three year programme based in 
NHS Fife exploring the use of various forms of process models in healthcare redesign. This longer term relationship provided an opportunity to gain greater access and feedback from clinical and management staff about the value of simulation and its implementation. These cases are compared to the reported implementation of a generic A\&E simulation across a number of sites in the United Kingdom (Fletcher et al, 2007).

\section{Accident and Emergency care in NHS Fife}

\section{Simulation of Accident and Emergency care in NHS Fife}

A major target for the NHS has been to reduce waiting times for Accident and Emergency (A\&E) care: the objective was that " $98 \%$ of patients should spend no longer than 4 hours in A\&E departments before being admitted, discharged or transferred" (Scottish Executive, 2005). While there is much debate (Bevan and Hood, 2006; Carvel, 2007; Cochrane, 2010) about the value of such performance management in the NHS and the effect of adopting quantifiable, simple measures, these targets have become the focus of much management effort. The need to model the flows of patients competing for limited resources within an environment of stochastic demand has led to simulation being used in various studies of A\&E departments (Gunal and Pidd, 2006; Fletcher et al, 2007). The assessment, treatment and possible admission of patients involve considerable interaction between the A\&E department and the other hospital departments. This poses a major modelling challenge: simulating the whole hospital is one approach but more commonly A\&E simulations strive to capture the critical characteristics of these interactions without a commitment to producing a model of the whole hospital in detail. The NHS Fife A\&E simulation has been described elsewhere (Bowers et al, 2009); the summary below focuses on the contribution of the simulation to the redesign process and the relationship with the client.

\section{Interaction with the client}

The simulation was developed over a period of 6 months as part of a larger three year programme involving various collaborative modelling ventures. The modelling team joined a group of managers and clinicians (the Flow Group) which met every two weeks to review progress towards the 4 hour target. The one hour meetings took place over lunchtime to minimise disturbance to patients and limit staff's time commitment. The clinicians were generally enthusiastic about their involvement in the redesign process as emergency care had been attracting adverse publicity across the UK. The Flow Group contained representatives of key staff from the A\&E department and associated services, led by a senior clinician. The modellers had excellent access to staff and data, while the regular meetings provided a forum for demonstrating and verifying prototype models. As in many other healthcare simulations (Baldwin et al, 2004), the model's development involved numerous iterations and discussions with many relevant staff. While time-consuming, this iterative engagement was most valuable in improving mutual understanding and communication between stakeholders.

Once the A\&E processes had been mapped, the Flow Group focused their attention on the volumes of flows and the capacities of different components of the A\&E system. Staff wanted a better understanding of the uncertainties and necessary contingencies required to deliver the 4 hour target. A demonstration simulation model was constructed and it was received enthusiastically, as indicated by the questions and suggestions for further 
refinements. In particular the Flow Group was keen that the model should be adapted so that it might be used by staff with minimal training in simulation, allowing independent experiments to assess alternative resource allocations without continual recourse to modelling expertise. Despite some misgivings amongst the modellers, it was agreed that such a simulation should be developed. The resultant model, capturing the key flows of patients as illustrated in Figure 1, was developed with an interface that highlighted the major decision variables. Variables such as the availability of key staff by time and day of week, and the volumes of patients, could be specified; this enabled staff to experiment with different staff shift patterns and the effect of variations in $A \& E$ demand.

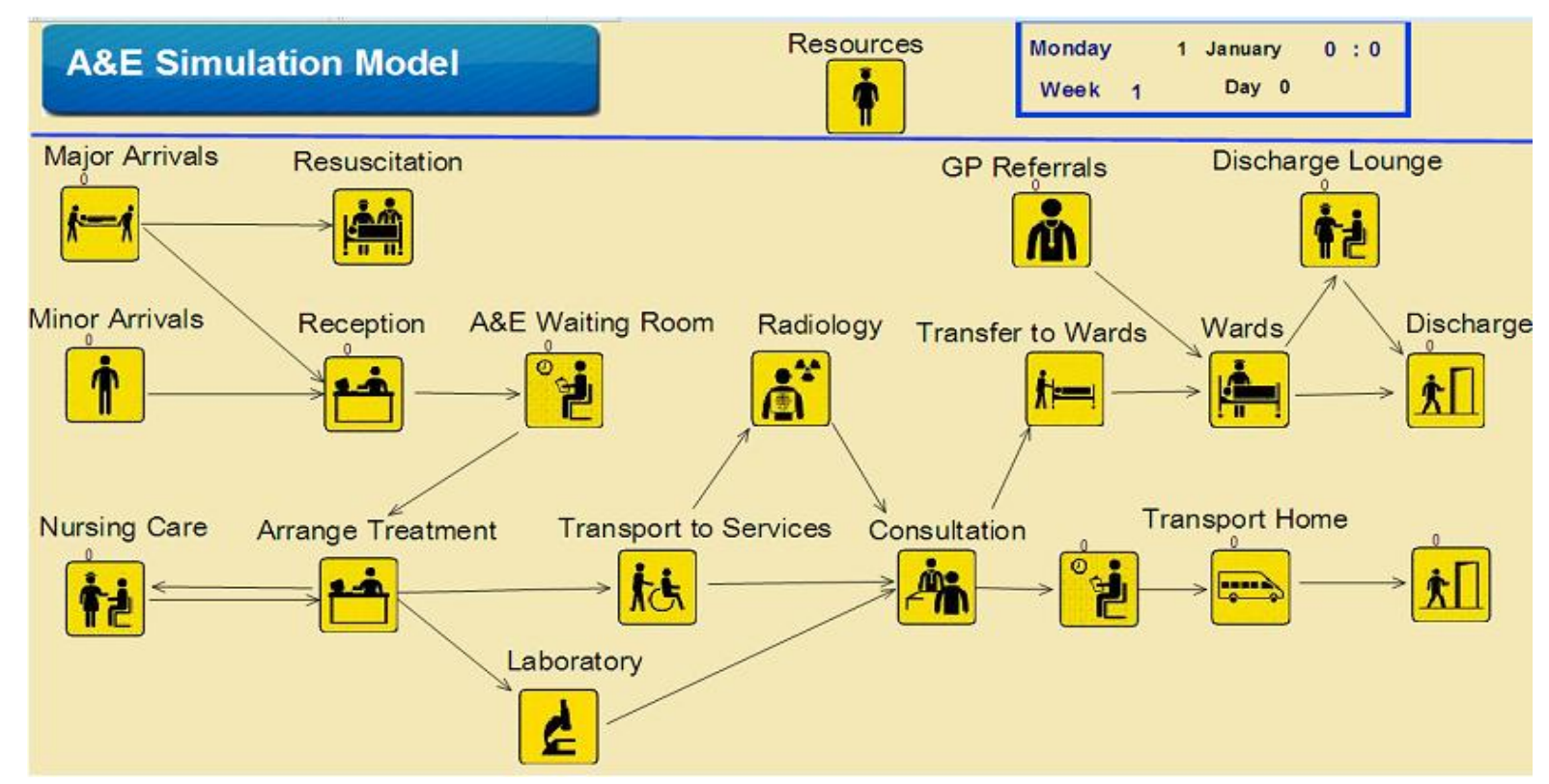

Figure 1 Accident and Emergency simulation model

\section{Modelling arrival patterns and schedules}

Analysis of past A\&E data revealed a distinctive distribution of arrivals, illustrated in Figure 2 , reflecting the patterns of everyday life and the working practices of primary care. "Major" and "minor" patients were distinguished since they typically have different requirements, which can be critical when modelling the workload implications for the A\&E department. A nonhomogeneous Poisson model was employed, capturing the time dependent nature of arrival pattern. Such demand models are useful in service industries, and unscheduled healthcare in particular, especially when examining the allocation of staff to match patient needs (Swisher et al, 2001; Alexopoulos et al, 2008).

The staffing schedules reflected many of the variations in demand, as illustrated by the availability of medical staff (before the modelling exercise), shown on the graph as the solid line in Figure 2. However, there were occasions when staffing might be better synchronised with the mean demand. Indeed, analysis of the timings of the breaches of the 4 hour target suggested that this mismatch of supply and demand could contribute to the delays experienced by some patients. Establishing a better fit of resources to demand is a classic topic for a simulation study, and staff were enthusiastic about its use in examining this problem. Assimilating the historic data enabled a simple comparison of hourly mean A\&E arrivals and staffing, as in Figure 2. However, a fully validated simulation was needed for a 
rigorous analysis exploring the stochastic nature of demand and assessing the aggregate workload implications of the patients' arrivals. But some A\&E staff felt that such refinements were not necessary: they claimed that the required changes were obvious and proceeded to alter the shift patterns based on a simple visual analysis of data comparing supply and mean demand. This analysis suggested allocating more staff at specific times, for example mornings (7-11am) and Friday and Saturday nights (>10pm). A rapid implementation was attractive since any new shift system had to be introduced before the arrival of the next cohort of junior doctors, otherwise any changes would have had to wait a further six months. Meanwhile, the development of the simulation model continued and it was eventually used to quantify the likely benefits of alternative staff allocations in terms of the proportions of patients meeting the 4 hour target; the rigorous study suggested that the new shift pattern would have just a small impact on the number of breaches of the target. This retrospective simulation analysis was of little practical value: the new shifts had already been introduced and judged to be a success, with staff citing experience from the first few weeks of their implementation. Discussion about the statistical significance and the possibility of other factors being responsible for the improvement in performance were relegated to a later study. While the simulation had not been employed in a classic scientific manner, its construction had certainly acted as a catalyst for change: assimilating the relevant data in a disciplined manner and promoting structured self reflection amongst the key staff. The simulation facilitated the collection of more quantitative and objective evidence substantiating the staff's own anecdotal analyses, identifying problems and helping elicit solutions.

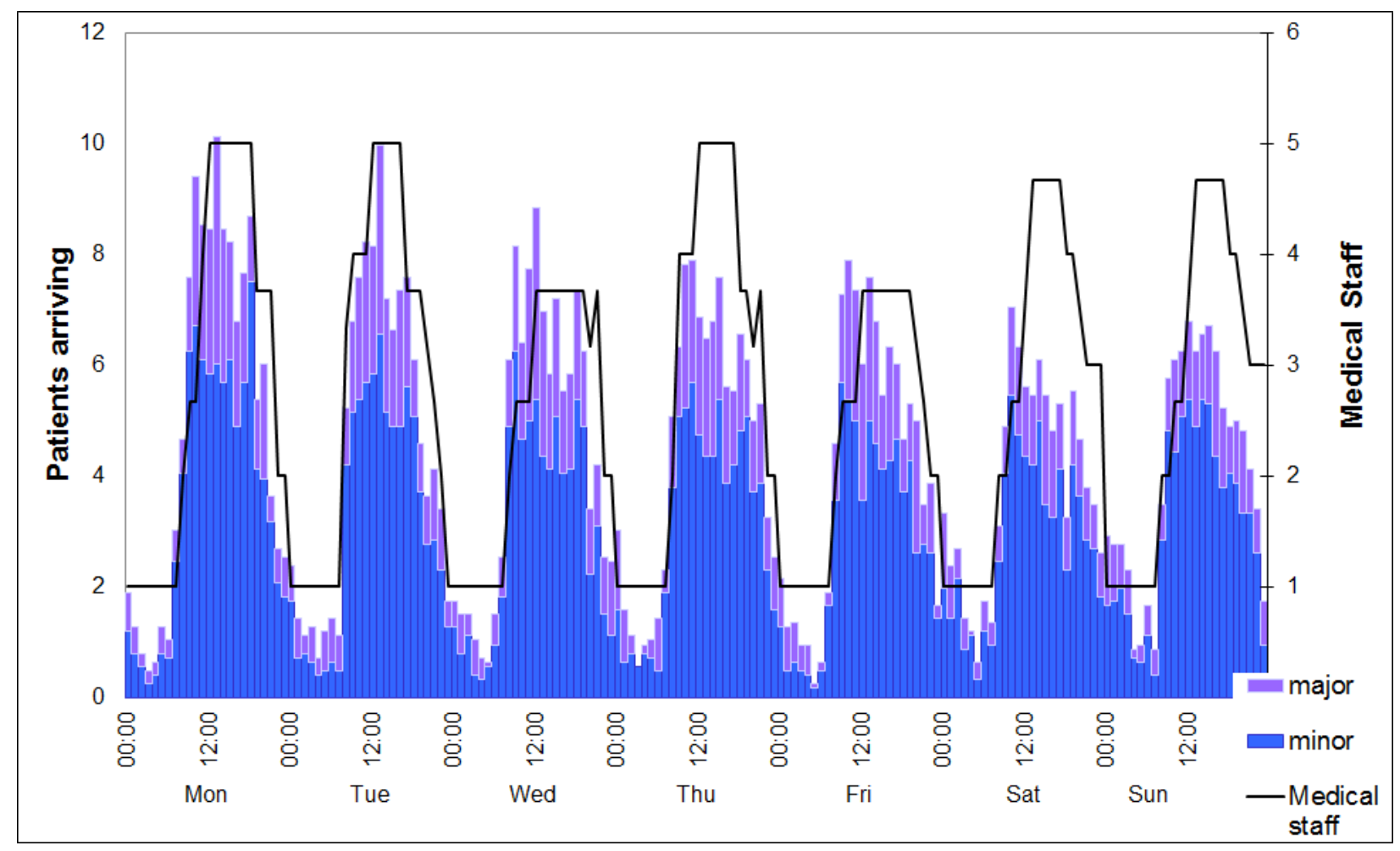

Figure 2 Hourly mean A\&E arrivals and staffing levels 
Defining the system boundary is often difficult and this was especially true of the A\&E simulation. Many A\&E activities interact with other departments and services, competing for common resources. A prime example was the admission of A\&E patients: while the majority of patients returned home, some were admitted requiring staff and resources, critically beds, from outside the A\&E department. In addition, A\&E competes with other hospital departments for services such as radiology, laboratory diagnostics and transport. One approach is to develop a whole hospital model. This greatly increases the effort and data requirements though it may be a practical route if a useful generic hospital simulation can be developed (Gunal and Pidd, 2007). The approach adopted in the NHS Fife A\&E simulation was to restrict the availability of resources reflecting the typical patterns of demand from competing departments: the study did not attempt to explore the reasons for these competing demands but just accepted them as a constraint on the availability of specified resources. However, modelling the interactions even in this simple manner stimulated insightful questions that prompted useful action; modelling the "transfer to wards" activity, see Figure 1 , required an understanding of staff working practices and the priorities accorded to the checking-in involved in admitting patients from A\&E. This debate prompted the Flow Group to arrange clearer protocols to clarify responsibilities and smooth the admission of patients. Such action might have been taken without the simulation but the modelling process again provided a vital catalyst.

\section{Contributions of the A\&E Simulation}

Technically, the A\&E simulation was a success. A validated user friendly model was developed to the specifications of the Flow Group. However, the model was not used to redesign A\&E to meet the 4 hour target. By the time the final model was tested and delivered the practical concerns had already been addressed. However, the process of developing the model did contribute to the Flow Group's understanding of the problems in A\&E and helped the group identify possible solutions. For example, the change of shift patterns to better reflect demand and the provision of clearer protocols for admission were both a direct result of the modelling process. As noted in other healthcare studies (van der Meer et al, 2005), the simulation encouraged a systemic view and stimulated clinical engagement, both being critical to effective healthcare redesign. The close relationship between client and modellers was very valuable; it facilitated the model design and validation but it also made it more difficult to manage expectations and refuse requests such as those for a user friendly tool for operational decisions. Both the client staff and modellers were keen to support each other and this led to an unwillingness to say "no". Some staff requests were contradictory: some wanted a validated, user friendly tool to support operational decisions; others wanted to proceed with implementing changes, such as the new shift patterns, without waiting for the rigorous analysis. A more contractual relationship might have led to better management of the study's scope. The lack of knowledge of simulation amongst the clients can result in unrealistic expectations but it is the modellers' responsibility to educate the client. Such failure to manage client expectations with consequent disappointment has been observed in other simulation studies (Robinson and Pidd, 1998). 


\section{Redesign in the orthopaedic outpatient clinic}

\section{Constructing an outpatient clinic simulation}

Although the A\&E simulation did not meet all expectations, its successes were sufficient for NHS Fife to retain its faith in the potential of simulation and support further applications. One notable subsequent study examined the design of the orthopaedic outpatient clinic. Outpatient activities have been examined in numerous previous studies (Lehaney et al, 1996; Clague, 1997; Bennett and Worthington, 1998; van der Meer et al, 2005). The interest in developing a simulation arose from a proposal to recruit an extra consultant in order to solve the problems in the orthopaedics' outpatient clinic. The clinic was failing to provide an acceptable service: patients would often have to wait an excessive time, with associated scenes of overcrowded waiting areas and stress for staff. It was suggested that the simulation might help determine whether the extra consultant would produce the desired improvement. The A\&E simulation provided a reasonable basis for the outpatient model, as both departments had a similar high level work pattern of assessment, investigation; diagnosis and treatment, however it was accepted that some refinement would be needed.

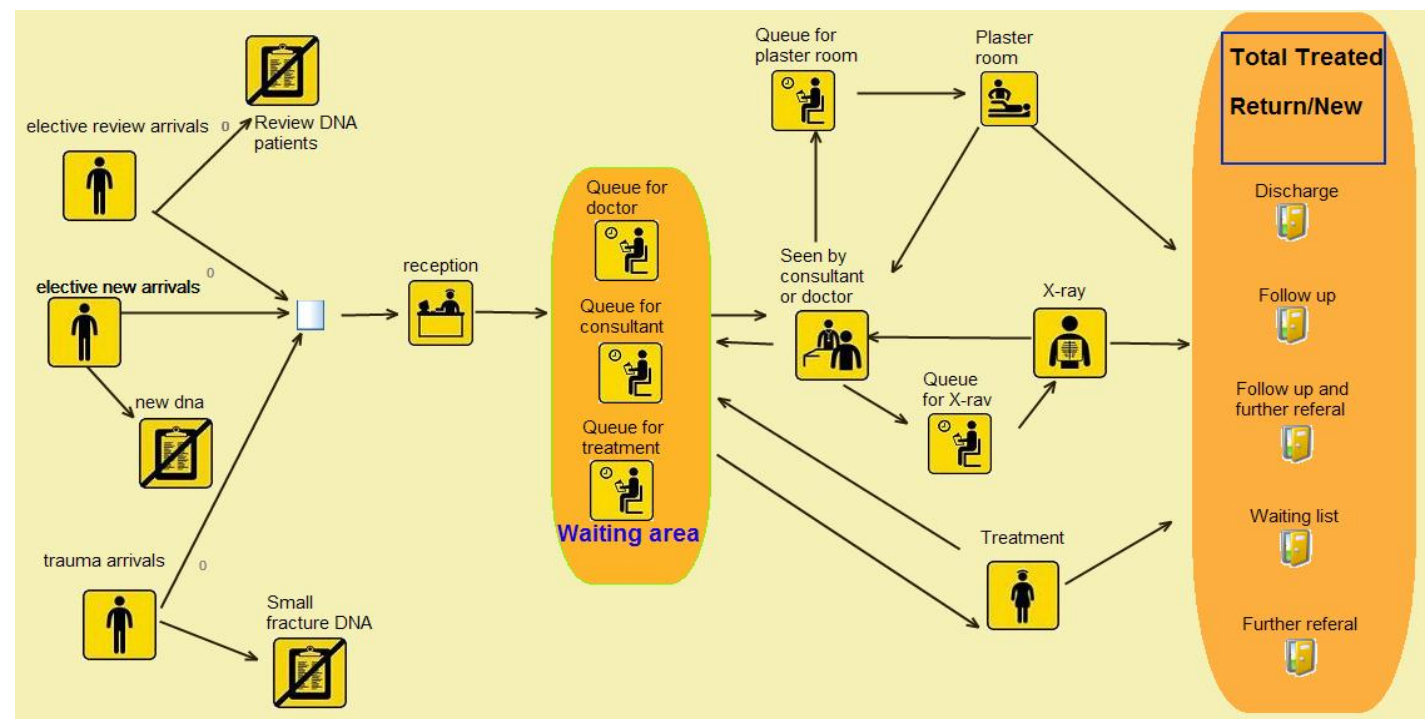

Figure 3 Orthopaedic outpatients' clinic model

The major difference between the A\&E and orthopaedic outpatients' clinic model was the nature of the demand. The A\&E patients' arrivals were all stochastic while many of the orthopaedic outpatients had more predictable needs and their arrivals could be scheduled. This scheduling was the major innovation with many of the other modelling components being reused from the A\&E simulation. There were three main categories of demand with flows of activities as illustrated in Figure 3. Two elective categories, the new and review or follow-up patients, could be scheduled well in advance. The major uncertainty was whether they would attend. The rate of "did not attend" (DNA) for the clinic was $8.7 \%$ for new patients, slightly less than the national average (ISD Scotland, 2011). The DNA rate is often a critical concern in the organisation of healthcare delivery, as recognised in other outpatient clinic simulations (Harper and Gamlin, 2003; Leharney et al, 1999). The simulation also incorporated the uncertainty about patients' arrival times relative to their appointment times. While this stochastic element was actually quite small, it was sometimes cited as justification 
for having a substantial number of early appointments to provide a buffer ensuring a continuous supply of work and hence maximising the utilisation of staff. The other category of demand, the trauma patients, was generated by referrals from A\&E the previous day; these were further distinguished as minor fractures or soft tissue injuries. Both of these subcategories had stochastic demand causing problems in managing a smooth flow of patients through the clinic.

The prospect of the simulation was welcomed by the orthopaedic clinic staff: many were unhappy with the existing organisation and resourcing of the clinic. A patient tracking exercise was initiated, collecting detailed timing data describing the progress of a sample of patients through the clinic. The enthusiasm of the staff was illustrated by the size of the exercise: detailed timings of the separate activities were recorded for individual patients and a sample of 657 were analysed. A prominent result was that waits of 1-2 hours were not uncommon but the time with a consultant could be less than 3 minutes. Such statistics confirmed the staff's anecdotal experience and the need for the simulation to examine options for improving the service.

\section{Exploring options for improving the clinic's reorganisation}

Amongst the various options explored, the simulation considered changes to the appointment system. This has been identified as an important aspect of healthcare clinic organisation in other studies (Bennett and Worthington, 1998; Cayirli and Veral, 2003; Moloney et al, 2006; Kaandorp and Koole, 2007). The existing system was based on a notional 20 minute appointment for a new patient and 10 minutes for a review, despite the reality of some patients having just a 3 minute consultation. However, no time was explicitly allowed for the trauma patients: they were just asked to arrive at start of the clinic. Alternative appointment schedules were tested using the simulation, producing a more even flow of work. In addition, the policy of specifying review appointments was examined. Clinical staff agreed that a much smaller proportion of patients should return to see the consultant; some could be seen by nurses whilst others might be told to return only if they experienced problems. It was also realised that it would be more appropriate for the soft tissue patients to return to A\&E for their outpatient care rather than attending the orthopaedics' outpatient clinic. These various suggestions were explored with clinical staff using the simulation to perform experiments to assess the likely benefits. This close working relationship with the clinical staff collecting data, discussing the logic and design of the model, and then using the model rather than always relying on the analyst, resulted in a large degree of confidence in the exercise. A programme of changes was implemented with numerous consequences for patients and staff: the more even flow of work combined with more careful selection of patients resulted in an enhanced service. This improvement is captured in the selection of performance measures of Table 1: the mean time that patients spent with a consultant increased significantly for new patients (from 9 to 14 minutes) though there was no change for other categories of patient. This improvement was gained by redirecting some review patients to be seen by specialist nurses while some trauma patients were followed up by the A\&E department, allowing the consultant to spend more time with new referrals. The proportion of new patients seen by a consultant increased from $69 \%$ to $87 \%$. 


\begin{tabular}{lcccccccc}
\hline $\begin{array}{l}\text { Patient } \\
\text { category }\end{array}$ & \multicolumn{2}{c}{ Number in sample } & \multicolumn{2}{c}{$\begin{array}{c}\text { Time with consultant } \\
\text { (minute:second) }\end{array}$} & \multicolumn{2}{c}{$\begin{array}{c}\text { \% of patients } \\
\text { seen by } \\
\text { consultant }\end{array}$} & \multicolumn{2}{c}{$\begin{array}{c}\text { Total medical contact } \\
\text { time (minute:second) }\end{array}$} \\
& Before & After & Before & After & Before & After & Before & After \\
\hline New & 111 & 38 & $9: 04 \pm 1: 19$ & $14: 39 \pm 3: 55$ & 69 & 87 & $15: 20 \pm 1: 56$ & $20: 19 \pm 3: 21$ \\
Review & 442 & 201 & $5: 19 \pm 0: 33$ & $4: 52 \pm 1: 03$ & 55 & 58 & $9: 52 \pm 0: 33$ & $8: 47 \pm 1: 12$ \\
Trauma & 104 & 72 & $4: 53 \pm 0: 51$ & $5: 26 \pm 0: 50$ & 49 & 53 & $9: 18 \pm 1: 07$ & $9: 51 \pm 1: 04$ \\
\hline
\end{tabular}

Table 1 Comparing performance at the outpatient clinic

$*$ mean $\pm 95 \%$ confidence interval

\section{Contributions of the orthopaedic outpatient clinic simulation}

The success of the orthopaedic simulation may be viewed as a good example of reuse (Robinson et al, 2004). There was an element of bespoke simulation development, notably in modelling the appointment systems and the patients' arrival distributions. However, many of components of the A\&E model were reused. The simulation models employed the same mechanisms to model the patients' movement through the various clinic activities and the capacity constraints imposed by the availabilities of key staff. The orthopaedic simulation also the "reused" the tacit knowledge and relationships developed during the A\&E simulation. An example of this knowledge was the appreciation that staff were often willing to engage in "patient-tracking": this has been a traditional approach to data collection in the NHS and many staff still have more faith in its reliability than newer data logging systems. Even when centralised data are available, such patient-tracking data can provide useful additional insights and also enhance the clinical staff's confidence in the exercise. This tacit knowledge of the value of patient-tracking was deployed at an early stage in the orthopaedic simulation model. Exploiting the reuse of such knowledge and components of the A\&E model enabled a rapid development producing a timely analysis that influenced the redesign of orthopaedic outpatient services.

\section{The roles and potential benefits of simulation}

\section{Distinguishing the roles}

The mixed records of the two simulation case studies can be compared with the full range of potential roles and benefits of discrete event simulation (DES), reflecting those of Operational Research in general (Pidd, 2001; Ormerod, 2002; Pidd, 2004). The potential roles and benefits are organised around two themes in Figure 4: predictive assessment, emphasising the "hard" or more traditional aspects of DES, and understanding, a key feature of "soft" modelling. Many case studies describe the application of DES in a "hard" role but it also has significant potential as a tool in "soft" OR interventions (Robinson, 2001). Illustrative studies are cited as examples of the various possible roles; in some cases the simulation is a clear example of a DES but other studies entail a combination of simulation and other techniques such as forecasting. 


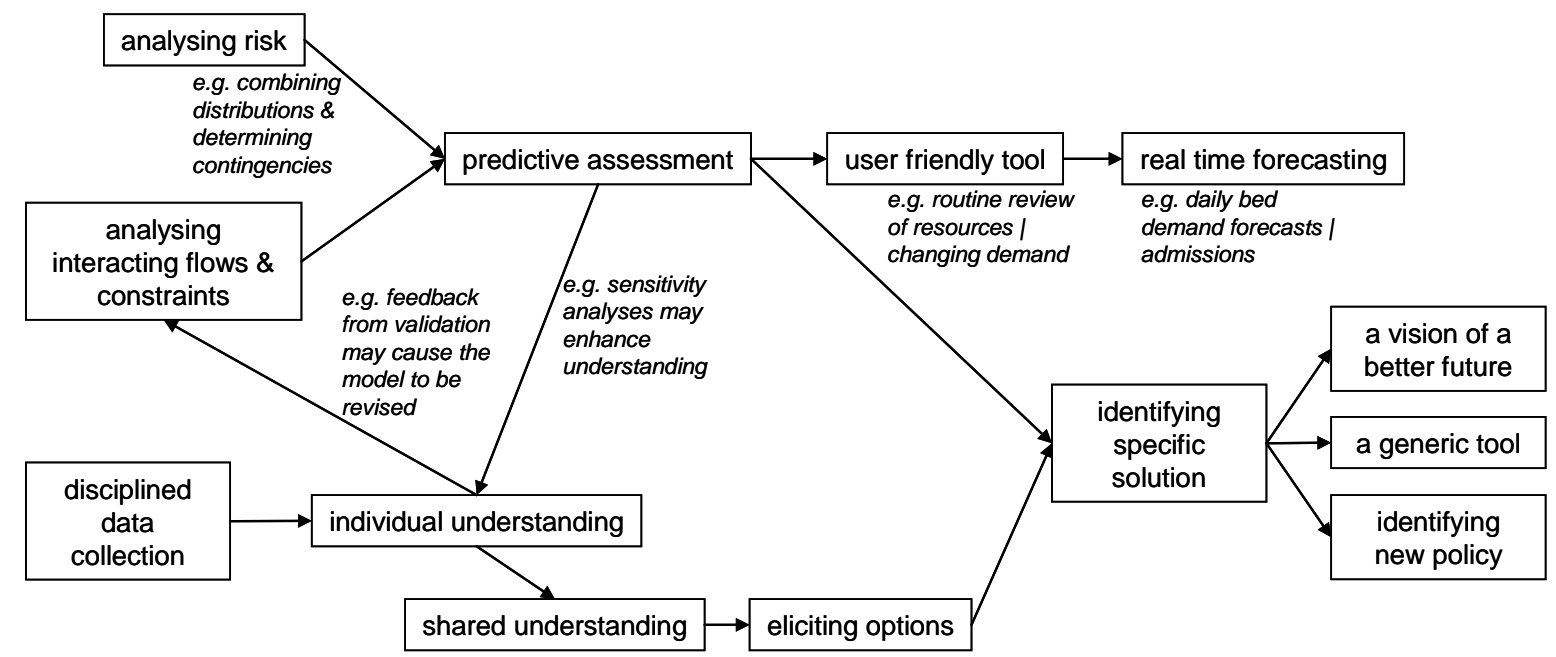

Figure 4 Mapping the roles and benefits of DES

\section{The traditional roles}

Traditionally DES in healthcare was viewed as a "hard" technique, analysing stochastic flows, providing a form of "decision mathematics" (Pidd, 2001). DES is especially valuable in determining appropriate contingencies, balancing the need to provide the required level of service with the desire to achieve a reasonable utilisation of resources. Such analysis is an useful input to the rational design of any service with a stochastic demand and emergency healthcare services in particular. The other distinctive characteristic of DES is the well proven capability to analyse flows of entities with interacting demands serviced by constrained resources. A clear analysis of the complex patients' journeys through the healthcare system is most valuable in diagnosing system problems and testing solutions. The combination of the ability to analyse risk and complex flows provide an objective basis for predictive assessment, determining the likely effect of any proposed changes to the system. In this role, a critical objective is to provide estimates of measures that can be used to inform decisions. The simulation's output may be summarised by measures such as quality adjusted life years or cost per life year saved (Davies et al, 2003). Often these "decision mathematics" capabilities are easier to sell to potential clients: the analytic power of simulation is distinctive and the deliverables are clear.

If the decision options are relatively limited and well defined, it may be desirable to provide the simulation with a robust interface such that the users themselves can repeat the simulation analyses. Equipped with such a user friendly tool, NHS clinical or management staff may update their resource allocation, reflecting changing circumstances without having to recall specialist simulation skills on every occasion. This capability may help ensure the sustainability of the simulation and ensure its longer term impact. In some applications, this predictive power may be taken further to provide a real time forecasting capability. The input parameters are updated regularly and the model is run to determine the consequences, such as the bed and staff requirement, with management taking appropriate action. However, the record of such healthcare modelling implementations in general is poor (Proudlove and Black, 2007) with there being only rare cases of a simulation becoming adopted as a routine decision support tool. 


\section{The softer roles}

Another common image of Operational Research is that of the application of scientific method in solving management problems (Pidd, 2001). In DES based studies this can be manifest as a disciplined, objective approach to data gathering: the analyst is compelled to ask the vital questions in order to construct the simulation model. If the model's design is realistic, the information requirements of the model should be identical to those of management facing the critical decisions. The discipline exerted by the model building should ensure that all the critical data are assimilated; even if the DES model itself is not completed the data are available and organised to help the decision making. In this role, DES can make a significant contribution to the call for "evidence-based management" in the NHS (Walshe and Rundall, 2001).

While the "decision mathematics" capabilities may be simplest to describe and sell to prospective clients, many claim that the greatest role is for DES as a tool for "design and synthesis" (Pidd, 2001). While system dynamics may be better known in this role, DES can also help individuals appreciate their own sub-systems and their place within the whole healthcare system under investigation. The representation of the system as a simulation model can help develop a shared understanding of both the problems and also encourage stakeholders to suggest options for improvement. These capabilities are not peculiar to DES, indeed other approaches to systems analysis and soft systems in particular could claim to be more appropriate in many cases. However, this soft approach to DES has been identified as being of particular relevance to the needs of healthcare management (Baldwin et al, 2004).

\section{Contributing to policy development and change management}

Simulation has the potential to combine both the "design and synthesis" with the predictive assessment to provide a powerful set of capabilities. This combination can both help elicit proposals and assess options providing the means to identify specific solutions to the local problems. Simulation may also be used to develop or explore more generic solutions, based on analyses of typical problems representative of many applications, identifying guidelines for policy, as in the organisation of acute services (Bowers and Mould, 2002). Furthermore, simulation may contribute to implementation: the simulation model of a future, better healthcare system with enhanced patient flows can provide a shared vision which can help facilitate change: the simulation of $A \& E$ in other studies has been used to engender a vision of a "98\% department"(Fletcher et al, 2007) encouraging a common belief that such a well organised service is an achievable target.

These roles and benefits may be claimed for a hypothetical healthcare simulation but does practice suggest that these claims are realistic? The case studies of the A\&E and orthopaedics' simulation in NHS Fife are assessed in the context of the potential benefits.

\section{Assessing the NHS Fife experience and comparison with a generic A\&E model}

\section{A generic A\&E simulation}

A major disappointment of the A\&E simulation in NHS Fife was the failure to deliver a timely model, available to provide rigorous, predictive assessment of options in support of 
the Flow Group's deliberations. An alternative approach would be to adopt a generic A\&E model, with some adaptation for local practice. Such a generic A\&E model was employed in a near simultaneous study in 10 different NHS Trusts in England, with mixed results (Fletcher et al, 2007). Some of the Trusts responded positively to the use of the generic simulation but other Trusts were less enthusiastic, with no constructive relationship being established between the modellers and the NHS staff. In both the NHS Fife study and the set of English NHS cases, the critical context was the NHS drive to achieve the 4 hour A\&E target. The simulations had very similar objectives and contexts, providing an opportunity to compare the approaches of the generic and bespoke simulation.

\section{A high level generic capacity planning simulation}

A further recent example of a generic healthcare simulation is the Scenario Generator, developed in a collaboration between the NHS Institute for Innovation and Improvement and the Simul8 corporation (NHS Institute for Innovation and Improvement, 2010). This simulation can be adapted to reflect local demographics and practice, in terms of the high level patient pathways, to produce estimates of requirements for key resources such as beds. Such a tool is valuable for capacity planning but it avoids the operational details which can be time consuming to model. This form of simulation is useful in the "predictive assessment" role and provides a "user friendly tool". However, avoiding the operational detail implies that the Scenario Generator cannot offer a route to the enhanced understanding of processes which might lead to options for increasing efficiency in patient care. It may also provoke local objections about systemisation and the need to retain clinical independence.

\section{Comparing the different approaches to simulation}

Using the broad categories of potential benefits summarised in Figure 4, the experiences of the simulations in NHS Fife are summarised in Table 2, and compared to those of the generic A\&E model. Both the NHS Fife and the generic A\&E simulation experienced the same phenomenon of the exacting timetable of the 4 hour A\&E target resulting in many changes having to be made in parallel. The target driven deadline precluded a more scientific approach to change management reducing the opportunities for simulation to be used in its more traditional role of the rigorous assessment of options. All three simulations applied DES in both "hard" and "soft" roles (Robinson, 2001), developing a tool for predictive assessment (the hard role) as well as facilitating understanding and eliciting redesign options (the soft role). It is possible for a single simulation to be successful in both roles, as in the orthopaedic study. However, this wide scope was one of the reasons for the NHS Fife A\&E simulation failing to meet the expanded expectations: the more rigorous validation required in the hard roles resulted in a longer development and a late delivery, reducing the model's value in the soft roles. Being over ambitious with the study's scope and trying to satisfy both "hard" and "soft" roles simultaneously can result in multiple disappointments, if not failures. 


\begin{tabular}{|c|c|c|c|}
\hline Potential benefit & $\begin{array}{l}\text { NHS Fife A\&E bespoke } \\
\text { simulation }\end{array}$ & $\begin{array}{l}\text { NHS Fife orthopaedic } \\
\text { reuse simulation }\end{array}$ & $\begin{array}{l}\text { Department of Health } \\
\text { generic A\&E simulation } \\
\text { (Fletcher et al, 2007) }\end{array}$ \\
\hline $\begin{array}{l}\text { Predictive } \\
\text { assessment }\end{array}$ & $\begin{array}{l}\text { The capability was realised } \\
\text { but too late for useful } \\
\text { application. }\end{array}$ & $\begin{array}{l}\text { The model provided timely } \\
\text { output, for example } \\
\text { quantifying the effect of a } \\
\text { new appointment system. }\end{array}$ & $\begin{array}{l}\text { Developed and validated } \\
\text { using a widespread survey. } \\
\text { The model was readily } \\
\text { populated with specific } \\
\text { NHS Trust data but local } \\
\text { differences in practices } \\
\text { hindered full validation. }\end{array}$ \\
\hline $\begin{array}{l}\text { Real time } \\
\text { forecasting }\end{array}$ & $\begin{array}{l}\text { Despite the efforts of the } \\
\text { modellers this became a } \\
\text { long term objective for } \\
\text { some of the client staff. } \\
\text { The model's accuracy is } \\
\text { unlikely to be sufficient for } \\
\text { such purposes. }\end{array}$ & $\begin{array}{l}\text { This was not specified as } \\
\text { an objective: analysts and } \\
\text { clients were more realistic } \\
\text { following the A\&E } \\
\text { experience. }\end{array}$ & $\begin{array}{l}\text { This was not a stated } \\
\text { objective; the expectations } \\
\text { were more realistic. }\end{array}$ \\
\hline $\begin{array}{l}\text { Understanding \& } \\
\text { developing options }\end{array}$ & $\begin{array}{l}\text { The model development } \\
\text { helped staff appreciate } \\
\text { problems and options for } \\
\text { improvement. }\end{array}$ & $\begin{array}{l}\text { Clinical staff co-operated } \\
\text { well and appreciated the } \\
\text { "system" view of their } \\
\text { clinic; their enthusiasm was } \\
\text { demonstrated in the large } \\
\text { scale patient tracking } \\
\text { exercise. }\end{array}$ & $\begin{array}{l}\text { In } 8 / 10 \text { cases the model } \\
\text { helped structure data } \\
\text { collection and hence } \\
\text { improved understanding. }\end{array}$ \\
\hline $\begin{array}{l}\text { Identifying specific } \\
\text { solutions }\end{array}$ & $\begin{array}{l}\text { The model was only } \\
\text { available in prototype when } \\
\text { needed. The prototype } \\
\text { models helped staff identify } \\
\text { solutions but were not able } \\
\text { to offer definitive guidance. }\end{array}$ & $\begin{array}{l}\text { Options were tested, e.g. } \\
\text { variations of the } \\
\text { appointment rules, to } \\
\text { determine r specific } \\
\text { recommendations. }\end{array}$ & $\begin{array}{l}\text { Scenarios were assessed } \\
\text { (in } 5 / 10 \text { cases). }\end{array}$ \\
\hline $\begin{array}{l}\text { A vision of a better } \\
\text { future }\end{array}$ & $\begin{array}{l}\text { Staff already believed they } \\
\text { could achieve a better } \\
\text { organised A\&E service. } \\
\text { The simulation just } \\
\text { reinforced this vision. }\end{array}$ & $\begin{array}{l}\text { Given its timely nature, the } \\
\text { simulation helped the clinic } \\
\text { staff visualise a better } \\
\text { organised orthopaedic } \\
\text { clinic. }\end{array}$ & $\begin{array}{l}\text { The simulation helped } \\
\text { develop a shared vision of } \\
\text { a " } 98 \% \text { department". }\end{array}$ \\
\hline A generic tool & $\begin{array}{l}\text { Presentations } \\
\text { generated have } \\
\text { interest but no other } \\
\text { implementation to date. }\end{array}$ & $\begin{array}{l}\text { Presentations have } \\
\text { generated significant } \\
\text { interest but no other } \\
\text { implementation to date. }\end{array}$ & $\begin{array}{l}\text { The model was developed } \\
\text { as a generic tool. }\end{array}$ \\
\hline Identifying policy & $\begin{array}{l}\text { The enhanced appreciation } \\
\text { of A\&E as a system may } \\
\text { influence policy, e.g. better } \\
\text { integration of support } \\
\text { services and A\&E. But no } \\
\text { substantial evidence as } \\
\text { yet. Care is needed to } \\
\text { avoid local biases. }\end{array}$ & $\begin{array}{l}\text { Discussions continue } \\
\text { elsewhere in NHS Scotland } \\
\text { to promulgate the lessons } \\
\text { from this study but with } \\
\text { limited success at present. }\end{array}$ & $\begin{array}{l}\text { The core simulation was } \\
\text { developed using a generic } \\
\text { understanding and data, } \\
\text { hence this offers a good } \\
\text { basis for examining policy. } \\
\text { But no evidence as yet. }\end{array}$ \\
\hline
\end{tabular}

Table 2 Realising the benefits of simulation

\section{The particular challenges of modelling in healthcare}

Healthcare modelling, and simulation in particular, appears to have a great potential but the reality can be disappointing. A critical challenge is the transfer of models from one 
application to another: success in one hospital does not mean that the model will be readily accepted in the next. The strong tradition of clinical independence is a critical characteristic of healthcare systems. In the NHS this has led to a variety of local practices and any model has to demonstrate that it can be tailored to match local conditions; this makes generalised modelling difficult and leads to expensive bespoke solutions (Pitt, 2009). Although there can be critical local differences, this may be exaggerated and result in a reluctance to adopt any practice "not invented here" (Brailsford, 2007). An attempt to transfer a model may be viewed as an example of a systemisation of healthcare and top-down reform. Some staff may welcome such an approach believing that a higher degree of systemisation can improve both quality and efficiency of care, but others view it as an attack on the independence that is vital to defending patients' interests. The classic tension between managers and clinicians may be problematic at times. However, this tension can also be valuable, balancing the needs of the individual patients and those of the population as a whole (Edwards et al, 2003). Medicalclinicians and medical-managers tend to oppose systemisation; general-managers, nursemanagers and nurse-clinicians generally support or are equivocal towards such approaches (Degeling et al, 2003). While the tradition of independence might be based in the clinical domain, it is not always easy to separate organisational and clinical change: when clinicians are identifying appropriate "best practice" they are also making decisions about the organisation of care and the allocation of resources (Degeling et al, 2003). This tension between managers and clinicians is not limited to the UK's NHS: it has been identified as a major barrier to change in many healthcare systems across the world (Delesie, 1998).

Politics and diverse objectives often present particular problems in healthcare modelling (Harper and Pitt, 2004). The delicate balance of power between management and clinicians implies many challenges for the reform of healthcare systems in general and the transferability of models in particular. The problems may be overcome but only by incorporating the clinicians' perspectives in the local implementation: generic models may always be viewed with suspicion and any modelling needs to plan for considerable effort liaising with local staff. The participation of client staff may be important in all modelling but the experience of simulation in NHS Fife and that reported elsewhere (van der Meer et al, 2005; Brailsford et al, 2009) suggests that effective stakeholder engagement is critical in healthcare. Redesigning healthcare systems typically involves many stakeholders ranging from patients to clinical and management staff; the NHS has an even greater range of stakeholders with numerous interdependent government agencies, notably social care. Engaging with all the relevant stakeholders can be time consuming and expensive but it is vital if the simulation is to be effective.

One key modelling decision is the choice of route to simulation implementation, typically bespoke, reuse or generic. Where resources allow, the bespoke route can be attractive. It provides the scope to incorporate all local variations in practice; this in turn offers a valuable vehicle for effective engagement, involving more stakeholders in constructing a model that reflects their experience. However, this process can be lengthy and it may be difficult to deliver timely results, producing a well constructed model too late to be of real relevance. The well designed generic model may be acceptable in some situations but there is a danger that even if it is technically valid, staff may be reluctant to accept any intervention based on a simulation that is perceived to represent external practice. The reuse route appears to be a reasonable compromise. It offers sufficient scope to for adjustment to local conditions, enabling stakeholder involvement in the model construction. However, it is also a relatively efficient form of modelling delivering timely results. 


\section{Conclusions}

Healthcare modelling faces particular challenges: genuine, fundamental variations in practice and an opposition to any suggestion of standardisation from some professional groups. Clinical independence may have great benefits for individual patient care but it makes the propagation of models challenging and costly: effective modelling in healthcare often requires more effort in engaging with the various stakeholders and tailoring the models to reflect local demands. Bespoke modelling can be expensive and fail to provide timely results; generic models may be viewed with suspicion. The reuse route offers a reasonable balance, combining modelling efficiency and timeliness with the opportunity to adapt to local practice, and provide a vehicle for the stakeholder engagement that is especially important in healthcare applications.

\section{References}

Alexopoulos C, Goldsman D, Fontanesi J, Kopald D, Wilson JR (2008). Modeling patient arrivals in community clinics. Omega-Int J Manage Sci 36(1): 33-43.

Baldwin LP, Eldabi T, Paul RJ (2004). Simulation in Healthcare Management: A Soft Approach (MAPIU). Simulat Model Pract Theory 12(7-8): 541-557.

Bennett JC, Worthington DJ (1998). An example of a good but partially successful OR engagement: Improving outpatient clinic operations. Interfaces 28(5): 56-69.

Bevan G, Hood C (2006). Have targets improved performance in the English NHS? Br Med J 332: 419-422.

Bowers J, Ghattas M, Mould G (2009). Success and Failure in the Simulation of an Accident and Emergency Department. J Simulat 3: 171-178.

Bowers J, Mould G (2002). Concentration and the variability of orthopaedic demand. $J \mathrm{Opl}$ Res Soc 53(2): 203-10.

Brailsford S (2007) Advances and challenges in healthcare simulation modelling.

Proceedings of the 2007 Winter Simulation Conference: 1436-1445.

Brailsford S, Bolt T, Connell C, Klein J, Patel B (2009) Stakeholder engagement in health care simulation. Proceedings of the 2009 Winter Simulation Conference: 1840-1849.

Carvel J (2007). Public sector targets to be scrapped. The Guardian 18 Jul 2007.

Cayirli T, Veral E (2003). Outpatient scheduling in health care: A review of literature. Prod Oper Manag 12(4): 519-549.

Clague J (1997). Improving outpatient clinic efficiency using computer simulation. Int J Health Care Qual Assur Inc Leadersh Health Serv 12(4-5): 197-201.

Cochrane A (2010). Scots deserve a better NHS for their money. Telegraph 21 Jan 2010. 
Davies R, Roderick P, Raftery J (2003). The evaluation of disease prevention and treatment using simulation models. Eur J Oper Res 150(1): 53-66.

Degeling P, Maxwell S, Kennedy J, Coyle B (2003). Medicine, management, and modernisation: a "danse macabre"? Br Med J 326(7390): 649-652.

Delesie L (1998) Bridging the gap between clinicians and health managers. Eur J Oper Res 105(2) :248-256

Edwards N, Marshall M, McLellan A, Abbasi K (2003). Doctors and managers: a problem without a solution? Br Med J 326(7390): 609-610.

Eldabi T, Paul R,Young T (2007) Simulation modelling in healthcare: reviewing legacies and investigating futures. J Opl Res Soc 58(2): 262-270.

Fletcher A, Halsall D, Huxham S, Worthington D (2007). The DH Accident and Emergency Department model: a national generic model used locally. J Opl Res Soc 58(12): 1554-1562.

Fone D, Hollinghurst S, Temple M, Round A, Lester N, Weightman A et al. (2003).

Systematic review of the use and value of computer simulation modelling in population health and health care delivery. J Public Health Med 25(4): 325-335.

Gunal MM, Pidd M (2006). Understanding accident and emergency department performance using simulation. In Perrone L F, Wieland F P, Liu J, Lawson B G, Nicol D M, and Fujimoto R M (eds). Proceedings of the 2006 Winter Simulation Conference: Monterey, CA. IEEE; Piscataway, NY, pp 446-452.

Gunal MM, Pidd M (2007). Interconnected DES models of emergency, outpatient, and inpatient departments of a hospital. In Henderson S G, Biller B, Hsieh M-H, Shortle J, Tew J D, and. Barton R R (eds). Proceedings of the 2007 Winter Simulation Conference: Washington, DC, CA. IEEE; Piscataway, NY ,pp 1440-1445.

Harper PR, Gamlin HM (2003). Reduced outpatient waiting times with improved appointment scheduling: a simulation modelling approach. OR Spectrum 25(2) 207-222.

Harper PR, Pitt MA (2004). On the challenges of healthcare modelling and a proposed project life cycle for successful implementation. J Opl Res Soc 55(6): 657-661.

ISD Scotland (2011). Inpatient, Day Case and Outpatient Activity: Outpatient and A\&E activity by specialty for Scotland and NHS Boards of treatment. http://www.isdscotland.org/isd/4156.html, accessed 19 May 2011.

Jahangirian M, Naseer A, Stergioulas L, Young T, Eldabi T, Brailsford S, Patel B, Harper P (2010) Simulation in health-care: lessons from other sectors. Operational Research, DOI: 10.1007/s12351-010-0089-8Online First ${ }^{\mathrm{TM}}$ available at http://www.springerlink.com/content/7615624526309606/

Jun JI, Jacobson SH, Swisher JR (1999). Application of discrete-event simulation in health care clinics. J Opl Res Soc 50(2): 109-123.

Kaandorp GC, Koole G (2007). Optimal outpatient appointment scheduling. Health Care Manag Sci 10(3): 217-229. 
Lehaney B, Kogetsidis HJ, Clarke S (1996). A case study of patient flows using Windowsbased computer simulation'. Work Study 45(6):17-21.

Lehaney B, Clarke SA, Paul RJ (1999). A case of an intervention in an outpatients department. J Opl Res Soc 50(9): 877-891.

Lowery J (1994) Barriers to implementing simulation in health care. Proceedings of the 1994 Winter Simulation Conference: 868-875.

Moloney ED, Bennett K, O'Riordan D, Silke B (2006). Emergency department census of patients awaiting admission following reorganisation of an admissions process. Emerg Med $\mathrm{J}$ 23: 363-367.

Naseer A, Eldabi T, Jahangrian M (2008) Cross-sector analysis of simulation methods: a survey of defense and healthcare Transforming Government 3(2): 181-189.

Naseer A, Eldabi T, Young T (2010) RIGHT: A toolkit for selecting healthcare modelling methods. J Simul, 4(1): 2-13.

NHS Institute for Innovation and Improvement (2010). Scenario generator project. http://www.institute.nhs.uk/scenariogenerator/general/scenario_generator_project.html, accessed 26 May 2010.

Ormerod RJ (2002). On the nature of OR: taking stock. J Opl Res Soc 53(5): 475-491.

Pidd M (2001). The futures of OR. J Opl Res Soc 52(11): 1181-1190.

Pidd M (2004). Contemporary OR/MS in strategy development and policy-making: some reflections. J Opl Res Soc 55(8): 791-800.

Pitt M, Dodds S, Bensley D, Royston G, Stein K (2009) The potential for operational research. Brit J Healthcare Man, 15(1): 346-351.

Proudlove NC, Black S (2007). OR and the challenge to improve the NHS: modelling for insight and improvement in in-patient flows. J Opl Res Soc 58(2): 145-158.

Robinson S (2001). Soft with a hard centre: discrete-event simulation in facilitation. $J$ Opl Res Soc 52(8): 905-915.

Robinson S, Nance RE, Paul RJ, Pidd M, Taylor SJE (2004). Simulation model reuse: definitions, benefits and obstacles. Simulat Model Pract Theory 12(7-8): 479-494.

Robinson S, Pidd M (1998). Provider and customer expectations of successful simulation projects. J Opl Res Soc 49(3): 200-209.

Scottish Executive (2005). An introduction to the unscheduled care collaborative programme. http://www.scotland.gov.uk/Resource/Doc/141079/0034895.pdf, accessed 19 May 2010.

Swisher JR, Jacobson SH, Jun JB, Balci O (2001). Modeling and analyzing a physician clinic environment using discrete-event (visual) simulation. Comput Opl Res 28(2): 105-125. 
van der Meer RB, Rymaszewski LA, Findlay H, Curran J (2005). Using OR to support the development of an integrated musculo-skeletal service. J Opl Res Soc 56(2): 162-172.

Walshe K, Rundall TG (2001). Evidence-based Management: From Theory to Practice in Health Care. Milbank Q 79(3): 429-457. 